Document downloaded from:

http://hdl.handle.net/10251/77508

This paper must be cited as:

Olmos Sanchis, JJ.; Salandin, A.; Más Estellés, J. (2016). Coherence of the assessment in the subject Physics Foundations on Computer Science. IATED Academy. http://hdl.handle.net/10251/77508.

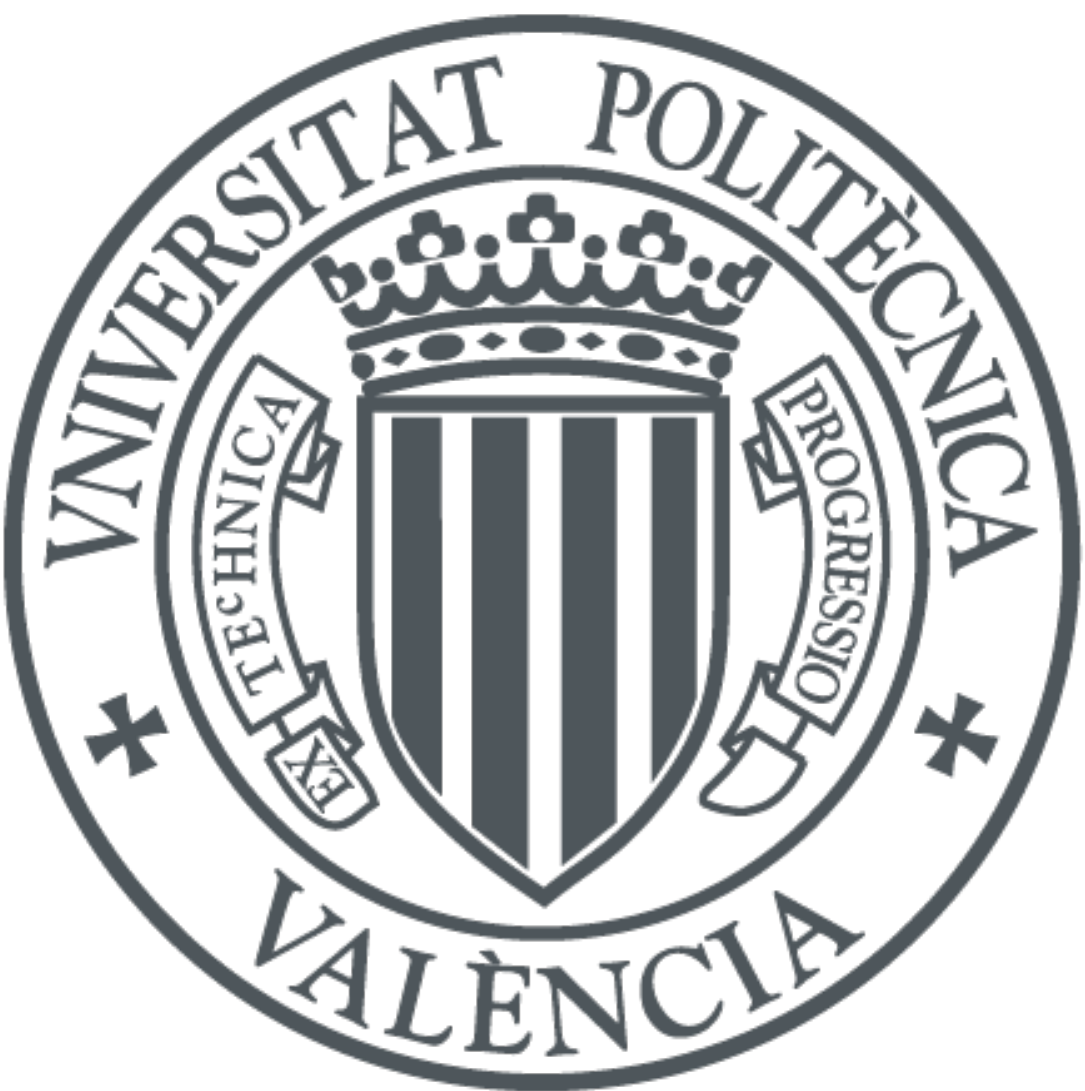

The final publication is available at https://iated.org

Copyright IATED Academy

Additional Information 


\title{
Coherence of the assessment in the subject Physics Foundations on Computer Science
}

\author{
Juan José Olmos-Sanchis, Andrea Salandin, Jorge Más-Estellés \\ Departament of Applied Physycs \\ Universitat Politècnica de Vàlencia \\ Valencia, Spain \\ jjolmos@fis.upv.es, ansa@ fis.upv.es, jmas@ fis.upv.es
}

\begin{abstract}
The creation of the European Higher Education Area (EHEA) and the introduction of new university degrees have promoted a new conceptualization and adaptation of the teaching methodology and the consequent and inevitable diversification of the assessment methods. Especially due to the introduction of continuous evaluation, many activities that had no direct influence on the final grade before, contribute now, to a greater or lesser extent, to the final grade. This set of information obtained during the course offers often great differences between them and other qualifications. Some differences are fully justified and other less justifiable. The main aim of this paper is comparing and analyzing results of different evaluation acts obtained by students in the subject Physics Foundations on Computer Science. Linear fitting of academic data (tests, mid-term and laboratory exams) have been compared with admission mark and previous studies at high school, traditionally identified as determinants for later academic performance. Two ad hoc parameters have been defined: the Results Deviation Parameter (RDP) and the Previous Studies Parameter (PSP). The analysis, even though it confirms a significant deviation from the expected ideal/linear result, offers results fairly coherent as well as the pattern of these results and previous academic studies of students.
\end{abstract}

\section{Keywords}

Assessment, coherence, admission mark, previous studies.

\section{Introduction}

The creation of the European Higher Education Area (EHEA) and the introduction of new degrees have fostered the search for new methodological references aiming to adapt the teaching methodology [7] and the consequent and inevitable diversification in evalua- tion methods. The new Bachelor and Master Degrees have adapted themselves to the new required challenges at training, social, economic and political level [4]. In order to promote a better learning environment and to train all competences (systemic, professional, cross) and furthermore with the aim of educating more "functional and adaptable" individuals $[2,6]$, the teaching environment has undergone major changes in recent years also due to a new national regulatory framework (RD 1393/2007 and RD 861/2010).

Particularly the introduction of continuous assessment has meant that activities that without direct weight on the final grade before, now contribute, to a greater or lesser extent, to it [5]. Among others, activities such as attendance, laboratory practice, solving exercises, both on controlled manner in the classroom (in-person class) or at home (distance learning) are now a days part of the final assessment in many subjects, according to new regulatory frameworks at universities. Some of these activities correspond more than others, to individual student work, while others correspond to jointly evaluated activities as expression of the need developing transferable competences and training student's skills, such as teamwork or effective communication.

This set of obtained information during the semester offers often great differences between qualifications. In some cases those differences are fully justified and in other less justifiable. It is true that given the wide variety of activities and skills tested, it is reasonable that students present a variable level of competences and skills. But we also can have some evaluation results which are much more contradictory as complementary.

With the aim to check and analyze the results of different evaluations the marks/results obtained in the subject of Physics Foundations on Computer Science will be studied. This subject of 6 ECTS is taught in the first semester of the first course in the Bachelor of Computer Engineering and the double degree in Computer Engineering-Business Administration (ADE). Contents include the physical fundamentals of the electric and the magnetic fields with a special 
regards to semiconductors and its main technical applications (diodes and transistors).

In this work an analysis of the results obtained by students in some of the various acts of evaluations realized throughout the semester is carried out. The studied evaluation acts, both with closed and open response, are only assessing individual and active student activities with a special regards to its coherence according the obtained results. Therefore the marks of a test and its corresponding partial examination as well as the test average and the average of mid-term or practical (laboratory) exams are compared. As the previous study (college) as well as the mark obtained at the Baccalaureate examination, have been traditionally identified as determinant for the academic performance [1,3], we have considered both factors in the analysis of the groups.

\section{Objectives and Methodology}

This study aims to check the type of relationship between the results of various acts of evaluation. In principle there should be a linear relationship, representable with a line through the origin and slope + $45^{\circ}$, between sets of data that are directly interrelated and reflect the reached level of student learning. For example it would be logical to think that a positive result in the first test of theory will have a direct influence on the result of the related mid-term exam which includes theory and related applicative problems.

A regression or simple linear fitting approximating the relationship between a first independent variable Y (for example the mark of test 1) and another independent variable $\mathrm{X}$ (mark of mid-term exam 1) will be performed. The setting provides this information:

- the slope of the regression line, $\mathrm{m}$

- the uncertainty of $\mathrm{m}, \Delta \mathrm{m}$

- the Y intercept, $b$

- the uncertainty of $b, \Delta b$

- the coefficient of determination, $\mathrm{R}^{2}$ which measures the fitting of the experimental data to the line.

This fitting has been carried out using the LINEAR ESTIMATION command, available in the Excel Application of Microsoft Office. We will study five simple correlations between marks:

- test 1 - mid-term exam 1

- test 2 - mid-term exam 2

- test 3 - mid-term exam 3

- average of tests - average of mid-term exams

- laboratory mark - average of mid-term exams.

Linear fitting settings provide two parameters ( $\mathrm{m}$ and $\mathrm{R}^{2}$ ) that indicate to what extent the data deviate from the expected ideal behavior (regression line with slope 1 and coefficient of determination 1). In order to summarize these parameters into one, we have defined a new parameter called Result Deviation Parameter (RDP), defined by values of $m$ and $R^{2}$ :

$$
R D P=\frac{A B S(1-m)+\left(1-\sqrt{R^{2}}\right)}{2}
$$

This parameter takes into account, on the one hand, the deviation of the slope from the expected value $(\mathrm{ABS}(1-\mathrm{m}))$, and secondly, the dispersion of the cloud of experimental data (1-SQRT $\left(\mathrm{R}^{2}\right)$ ). The RDP is defined as the average of both contributions. RDP is always positive, corresponding a zero value to perfectly aligned points on the theoretical line.

Moreover, the impact of previous studies on student's performance in university studies has been characterized by two other factors:

- home high school according to previous studies (origin). The faculty sets as most recommended previous studies the Scientific and Technical Baccalaureate even if different studies are possible. For this reason we have calculated, for each of studied group, the rate of students from the Technical and Scientific Baccalaureate (TSB) as a decimal; TSB can range between 0 and 1 .

- the average admission mark (AAM) to the degree of each of the studied group. AAM can vary between 5 and 14

In order to define a single parameter that takes into account both factors, we have defined the Parameter of Previous Studies (PPS) as the average of both:

$$
P P S=\frac{T S B / 10+A A M}{2}
$$

The PPS may range between 0.25 and 1.2 moving closer to 1.2 if students of the sample mostly come from Scientific and Technical High Schools and show better admission marks.

\section{Experimental Approach. Description of the sample.}

The study was carried out in the first semester of the academic year 2015/16 on students of the subject Physics Foundations on Computer Science (four groups: C, D, E and F), Bachelor degree in Computer Engineering, and students of the same subject of the double Bachelor in Computer Engineering and Business Administration (ADE group), running with just one group. Furthermore the $\mathrm{E}$ group is labeled as Academic High Performance (AHP) and lectures are taught in English with a small group organization. Those groups were chosen because they are a repre- 
sentative sample and at the same time were fully or partially taught by the authors. The total enrollment in these groups was 237 (out of 512 students). A small amount has not been included in the sample due to lack of data. The final amount of pupils is 190 (37\% of total).

The assessment of the subject is based on four elements:

- three objective type tests (20\% of the final mark)

- three mid-term exams with open response, with questions on theory and application problems (TP) (50\% of the final grade).

- $\quad$ work at the laboratory $(20 \%)$, split into two parts (report of practical with $10 \%$ and final individual laboratory exam with $10 \%$ ).

- portfolio of activities developed during the lectures or at home $(10 \%)$.

Obviously, the tests are more related to knowledge and terminology of the subject, while mid-term exams are more focused on demonstrations, direct applications of the theory and analysis and solving of problems.

This paper analyzed the results corresponding to the test, the mid-terms and the individual laboratory exams. The data have been conveniently depersonalized, with the results analyzed for each student, for the three grades of the test (T1, T2 and T3), the three marks for the mid-term exams (TP1, TP2 and TP3) as well as the mark of the individual final laboratory exam (LE). In addition, each student has been also asked about the previous studies, with 7 different possibilities, according to the type of home high school (Scientific or Technical, Live Sciences, Social Sciences, Humanities, Arts, Vocational Training, Other).

Since the origin of the students seems to be a very relevant factor in the results, we calculated for each group, the rate of students from the Technical and Scientific Baccalaureate (TSB) as well as the average admission mark for each of the studied groups (AAM). Data of the sample group composition are summarized in the table 1 :

\begin{tabular}{|c|c|c|c|c|}
\hline \multirow{2}{*}{ Group } & \multicolumn{2}{|c|}{ students } & \multirow{2}{*}{ AAM } & \multirow{2}{*}{ TSB } \\
\cline { 2 - 3 } & enrolled & sample & & \\
\hline ADE & 42 & 39 & 10,5 & 0,62 \\
\hline C & 55 & 50 & 10,3 & 0,76 \\
\hline D & 56 & 43 & 9,2 & 0,77 \\
\hline E & 26 & 24 & 10,7 & 0,88 \\
\hline F & 50 & 34 & 9,0 & 0,62 \\
\hline Total/average & 229 & 190 & 9,8 & 0,72 \\
\hline
\end{tabular}

Table 1: Sample data per group and total
The Technical and Scientific Baccalaureate is the most common previous study origin with an average level of $72 \%$ and the average access mark is 9,8 of 14.

\section{Results and discussion}

From available data was on first graphed the results on test (T) against the results on theory and problems exam (TP) for each of three midterm exams. On next graph is shown the linear fitting of both variables corresponding to first midterm exam for every student of every studied group.

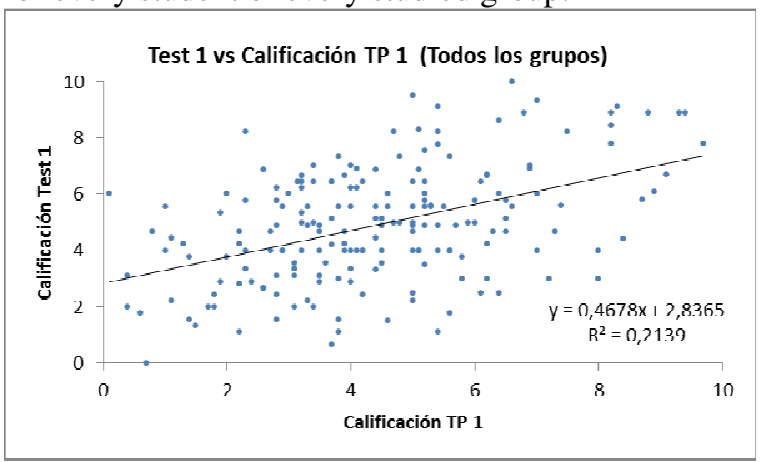

Figure 1: Linear fitting of test1 mark against TP mark of first midterm exam. Result of students of every group.

The linear fitting over these data shows a regression line with a slope $\mathrm{m}=0,47 \pm 0,07$ and a coefficient of determination $\mathrm{R}^{2}=0,21$. These results can be easily compared with those expected for an ideal behavior where every student would get equal mark on test and theory and problems exam $\left(m=R^{2}=1\right)$. As it could be expected, a deviation between the got and the expected behavior is got, that a priori could be due to several factors:

- A low coherence between the test and the theory and problems exams, both having different difficulty levels, resulting on different marks.

- The fact that both exams require different skills, resulting on different marks.

- A different training of students on both exams, resulting on different marks.

- The data where the exams are carried out; either because both assessments are carried out the same (or different) day or because on the timetable of exams, these assessments are carried out before or after the exams of another subjects.

- The fact that the students have available the solved exams of theory and problems corre- 
sponding to previous exams but not those of previous tests.

The same graphing and linear fitting has been also carried out separately for each group for each midterm exam. These results are shown on next table:

\begin{tabular}{|l|l|l|l|l|l|l|}
\hline GROUP & ADE & C & D & E & F & EVERY \\
\hline \multicolumn{7}{|c|}{ MIDTERM EXAM 1} \\
\hline $\mathrm{m}$ & 0,67 & 0,64 & 0,50 & 0,62 & $-0,12$ & 0,47 \\
\hline$\Delta \mathrm{m}$ & 0,17 & 0,17 & 0,12 & 0,20 & 0,18 & 0,07 \\
\hline $\mathrm{R}^{2}$ & 0,29 & 0,23 & 0,28 & 0,30 & 0,01 & 0,21 \\
\hline \multicolumn{7}{|c|}{ MIDTERM EXAM 2} \\
\hline $\mathrm{m}$ & 0,43 & 0,44 & 0,55 & 0,50 & 0,25 & 0,45 \\
\hline$\Delta \mathrm{m}$ & 0,10 & 0,09 & 0,11 & 0,13 & 0,22 & 0,05 \\
\hline $\mathrm{R}^{2}$ & 0,31 & 0,32 & 0,38 & 0,40 & 0,04 & 0,28 \\
\hline \multicolumn{7}{|c|}{ MIDTERM EXAM 3} \\
\hline $\mathrm{m}$ & 0,68 & 0,62 & 0,57 & 0,80 & 0,18 & 0,62 \\
\hline$\Delta \mathrm{m}$ & 0,07 & 0,11 & 0,09 & 0,22 & 0,13 & 0,05 \\
\hline $\mathrm{R}^{2}$ & 0,74 & 0,42 & 0,51 & 0,38 & 0,06 & 0,49 \\
\hline
\end{tabular}

Table 2: Results of linear fitting graphing the mark of test against the mark of theory and problems for each midterm exam on every group.

By graphing these results, the behaviour of different groups can be more clearly seen:

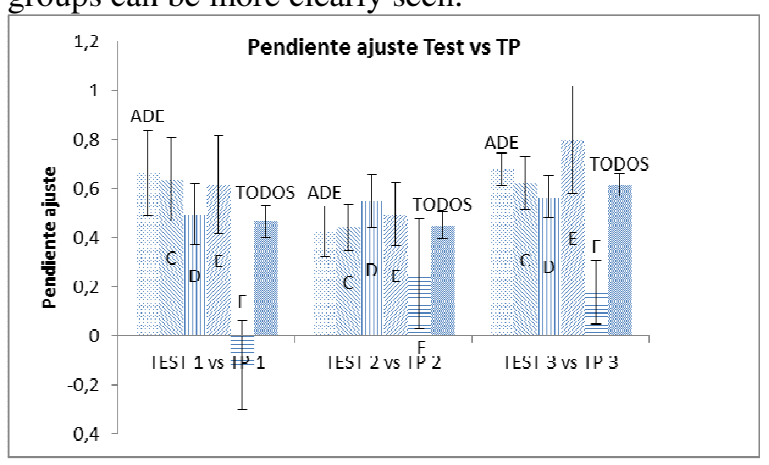

Figure 2: Slope of linear fitting of test1 against TP exam.

It is noticeable, on first, that every group but the $\mathrm{F}$ group shows behaviour on those analysed parameters that could be described as similar. On first midterm exam, the slopes of fittings lie around 0,5 with coefficients of determination around $0,2-0,3$ but the group $\mathrm{F} ; \mathrm{F}$ group shows a negative slope and a coefficient of determination near zero, thus indicating a fairly relationship (even none) between the results of both marks.

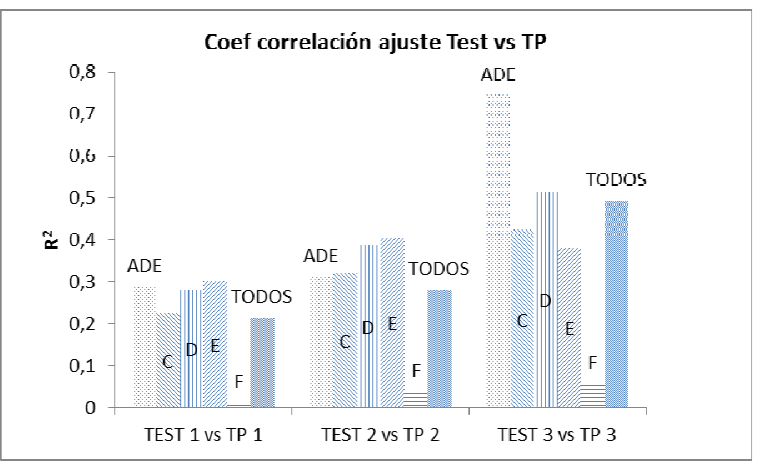

Figure 3: Coefficient of determination of linear fittings of test against TP exams.

On the three midterm exams, the slope of linear fittings show similar values if we take in account the uncertainties; may be a slightly increasing can be seen on third midterm exam.

About the got results, even though we haven't any other value to be compared, we think that they can be qualified as low values. But from the maintenance or little increasing of $\mathrm{m}$ and the increasing of $\mathrm{R}^{2}$ along the year, we can state that the students feel stronger relationship between theory and problems when the course progress; the coefficient of determination between test and TP exams increases along the year. Even on group $\mathrm{F}$ appears this behavior. Although we don't find a convincing reason for this fact, it could be related to the adaptation of students to their new university life and the acquisition of new knowledge coming from other subjects. It must be highlighted that our subject is taught on first semester when the students are still being adapted to the university, and it isn't strange that they improve their adaptation and working methods.

The low value of coefficient of determination could be indicative that the students don't relate the questions of test with those of theory and problems, may be because of a lack of connection between the theory and its application on demonstrations and resolution of problems. Nevertheless, it seems that this connection increases on every studied groups when the course progress.

It is also surprising that the determination coefficient on third midterm exam of group ADE is very high $(0,74)$ compared with those of before exams. This fact could be related to the higher demand of tutorship by the students of this group (higher incoming heterogeneity and higher incoming mark); we think that the tutorship can homogenize the knowledge of students and then increase their determination coefficient. 
Anyway, the fact that the results on two different exams are compared through two different parameters, introduces a difficulty that we have tried to solve by summarizing both parameters in only one; the already said Results Deviation Parameter (RDP), ranging between 0 for an ideal fitting to a straight line, and 1 for a fitting of a cloud of points randomly distributed. The graphing of RDP for each group and each exam can be seen on figure 4 , with the said results.

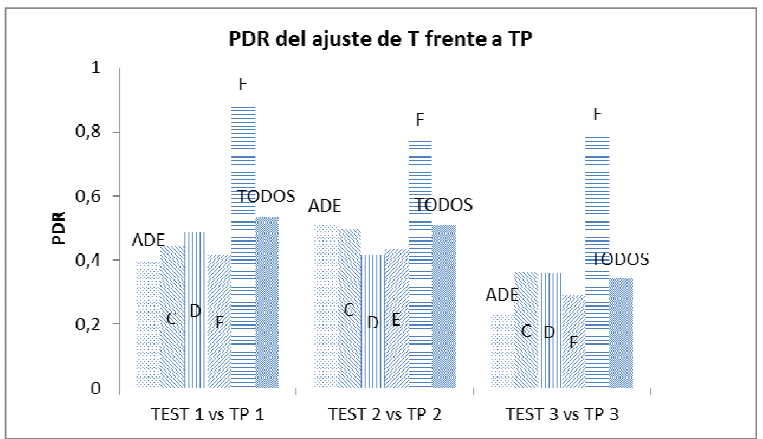

Figure 4: Results Deviation Parameter for linear fitting of tests against the TP exams.

Besides the tests and TP exams have also been studied the results of individual laboratory exams. At this point, our opinion is that as different skills are assessed, a lower relationship between them could be expected.

For this reason, we have computed an only mark as the average of tests and TP exams for the set of midterm exams. Therefore, we have performed a linear fitting of laboratory mark against this average mark for each group. Graphing of RDP of this fitting for each group can be seen on figure 5 .

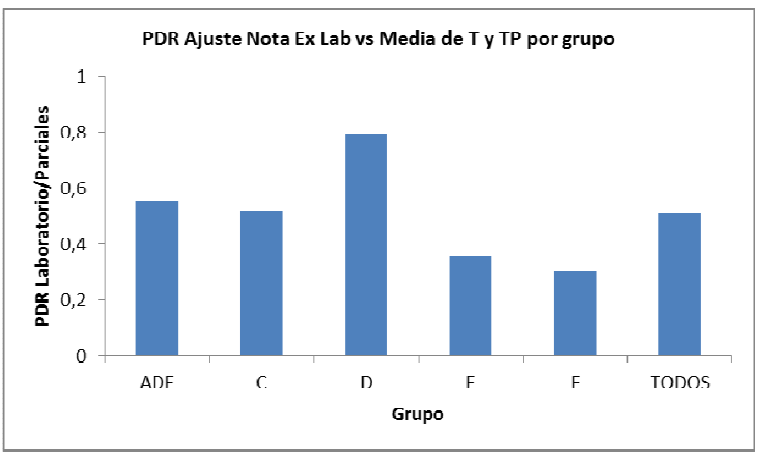

Figure 5: Results Deviation Parameter for linear fitting of laboratory mark against the average of tests and TP exams (set of three midterm exams).

It is noticeable that the $\mathrm{F}$ group shows a higher correlation between laboratory mark and tests and TP exams. On this group, teachers of theory and laboratory are different, and the same situation occurs on group D, with a very high RDP; instead, on group E, with the same teacher for theory and laboratory, RDP is also low, reason why this factor doesn't seem to be determinant. The behaviour of set of groups is scarcely uniform, with RDP ranging from 0,3 to 0,8 . The average for the set of every groups is 0,5 , higher slightly than the RDP found for the fitting of tests against TP.

From these results we can't attribute to this difference of teacher between laboratory and theory the different relationships on the corresponding marks. We think that these differences are mainly due to the different skills required on both tasks (laboratory and TP).

In order to check this idea, we tried to relate the before fittings with the previous studies of students before incoming on our school; may be the different previous studies could justify different skills.

The previous studies of students have been characterized through two factors considered as determinant for the academic performance on first year of university studies: the incoming mark on the grade and the previous studies. Another time, in order to avoid analysis depending on two different factors, we have summarized the incoming mark and the ratio of students coming from Technical and Scientific Bachelor in only one parameter, the already defined Previous Studies Parameter (PSP). Data of each group were given when the sample was described; group ADE, for example, shows a very high incoming mark, but the lowest ratio of students coming from the Technical and Scientific Bachelor. If we graph RDP of fitting of test and TP against PSP (Figure 6), every group lie nearby, indicative that the students with similar origin and mark correlate test and TP with similar parameters.

We think that this result validates the coherence of exams carried out. Only group F, showing a high PDR with similar students is far of the general behaviour.

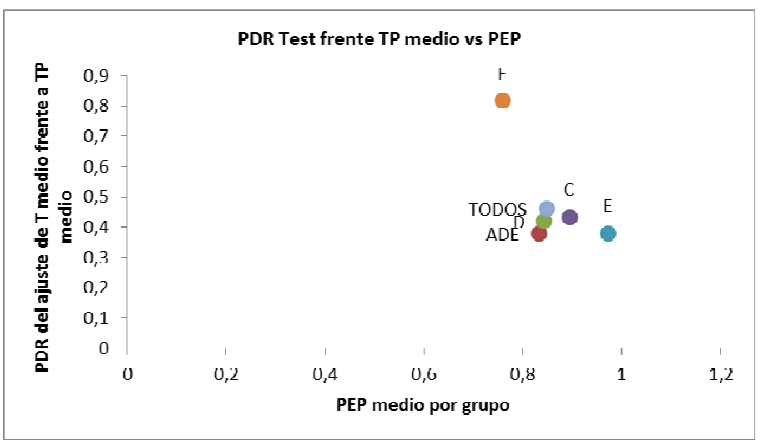

Figure 6: RDP of fitting of tests against TP (average of three midterm exams) against PSP for each group.

But the graphing of average of tests and TP against PSP shows a clear pattern, where this average 
increases with PSP, as it has been observed on too many studies [3]. This graph can be seen on figure 7 .

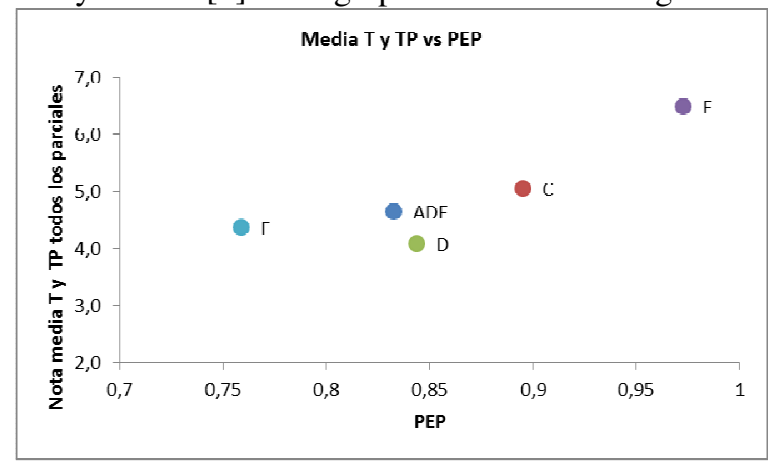

Figure 7: Average of tests and TP on three midterm exams against PSP.

The same behavior can be observed by graphing the average mark of laboratory exam for each group against PSP. A slightly increasing on the expected behaviour occurs on group $\mathrm{E}$, but even though on the laboratory exams are required some different skills that those of other different exams, also the laboratory mark directly correlate with PSP. On figure 8 can be observed this correlation.

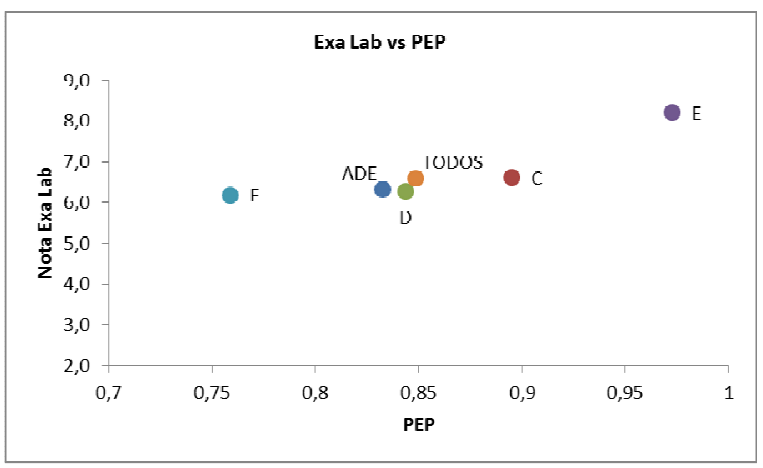

Figure 8: Average mark of laboratory mark against PSP for each group.

\section{Conclusions}

The analysis of correlation between different exams by using a linear fitting shows results usually coherent, even though on this study appear groups whose results can be explained with difficulty.

The correlation between two exams can be properly analysed by using the Results Deviation Parameter (RDP), which takes in account both the slope of linear fitting as its determination coefficient.

The correlation between tests and theory and problem exams increases when the year progress; we attribute this increasing to the integration of knowledge between theory and problems by the students.
The RDP of laboratory mark and the theory and problems exams shows a higher dispersion than the tests and theory and problems exams, thus indicating that both exams require different skills.

The previous curriculum of students and their incoming mark can be properly characterized through the Previous Studies Parameter (PSP), which takes in account both factors.

The correlation between tests and theory and problems exams is roughly independent of previous curriculum and incoming mark of students (PSP), which validates the coherence between both types of exams.

The laboratory mark shows a direct relationship to the previous studies of students (PSP).

\section{Acknowledgements}

To the Escola Tècnica Superior d'Enginyeria Informàtica de la Universitat Politècnica de València by its supply of the average incoming mark by group and by its financial support.

\section{References}

[1] R. Alcover, J. Benlloch, P. Blesa, M.A. Calduch, M. Celma, C. Ferri, J. Hernández-Orallo, L. Iniesta, J. Más, M.J Ramírez-Quintana, A. Robles, J.M. Valiente, M.J. Vicent, L.R. Zúnica. Análisis del rendimiento académico en los estudios de informática de la UPV aplicando técnicas de minería de datos. Actas de las XIII Jornadas de Enseñanza Universitaria de la Informática, Jenui 2007, pp. 163 - 170, Teruel, julio 2007.

[2] A. Hernández Fernández, N. González Fernández, S. Guerra Liaño. Diseño de un portafolio en la formación universitaria por competencias. Revista de Psicodidáctica, vol. 11 (2), pp. 227238, 2006.

[3] Jorge Más Estellés, Rosa Alcover Arándiga, Adriana Dapena Janeiro, Alberto Valderruten Vidal, Rosana Satorre Cuerda, Fernando Llopis Pascual, Tomás Rojo Guillén, Rafael Mayo Gual, Miren Bermejo Llopis, Julián Gutiérrez Serrano, Jordi García Almiñana, Edmundo Tovar Caro, Ernestina Menasalvas Ruiz. Rendimiento académico de los estudios de informática en algunos centros españoles. Novática, 204, pp. 55 - 61. Marzo-Abril 2010.

[4] A. Navío Gámez. Propuestas conceptuales en torno a la competencia profesional. Revista de Educación, vol. 337, pp. 213-234, 2005.

[5] Isabel Nepomuceno, Juan A. Nepomuceno, Antonia M. Reina Quintero, Jorge García Gutiérrez. Metodología de evaluación continua en la asignatura de Fundamentos de Programación: un cambio de evaluación enfocado al desarrollo 
de competencias. Actas de las XVIII Jornadas de Enseñanza Universitaria de la Informática, Jenui 2012, pp. 393 - 396, Ciudad Real, julio 2012. Póster.

[6] Office of Institutional Assessment. Assessing competence in six areas at Mason: a summary of the first cycle: 2002-2006. Focus, vol. 12 (1), pp.1-6, 2007.

[7] M. Olvera Treviño, S. Reyes Salina, S. Zavala Elvia. Estrategias basadas en el aprendizaje cooperativo y en la metrología para el laboratorio en el trabajo experimental. VIII International Congress on Investigation about Didactic of Sciences, pp. 3476-3482, 2009. 